\title{
STUDI KAWASAN KONSERVASI DI KOLAM TAMAN PINTAR SEBAGAI BAHAN AJAR LKS UNTUK MENINGKATKAN HASIL BELAJAR SISWA
}

\author{
Eria Irmawati ${ }^{1 *}$, Aceng Ruyani ${ }^{1}$, Ariefa Primaryani ${ }^{1}$ \\ ${ }^{1}$ Program Studi Pendidikan Biologi, Fakultas Keguruan dan Ilmu Pendidikan, Universitas Bengkulu \\ e-mail : eriairmawati95@gmail.com
}

\begin{abstract}
Abstrak
Penelitian ini bertujuan untuk 1) mendeskripsikan pengaruh kawasan konservasi di kolam Taman Pintar terhadap laju pertumbuhan kura-kura Sumatera dan 2) mengetahui peningkatan hasil belajar siswa menggunakan bahan ajar LKS berdasarkan hasil studi kawasan konservasi ex-situ kura-kura Sumatera di kolam Taman Pintar. Jenis penelitian ini adalah penelitian deskriptif kuantitatif. Berdasarkan hasil analisis diperoleh data bahwa komponen-komponen lingkungan yang ada di kawasan konservasi ex-situ kura-kura Sumatera di kolam Taman Pintar berpengaruh terhadap laju pertumbuhan kura-kura yang dapat dilihat peningkatan ukuran morfometri tubuh pada satu tahun terakhir. Selain itu hasil belajar siswa mengalami peningkatan setelah menggunakan bahan ajar LKS berdasarkan studi kawasan konservasi di kolam Taman Pintar. Adapun persentase nilai pretest siswa yaitu 48,4\% dan pada nilai postest meningkat menjadi $90.9 \%$.
\end{abstract}

Kata Kunci: Kawasan konservasi, Laju Pertumbuhan, Lembar Kerja Siswa, Hasil Belajar

\begin{abstract}
This study aims to descibe 1) the influence of ex-situ conservation areas of Sumatran turtles in Taman Pintar to the growth rate of Sumatran turtles and 2) to knowing the improvement of student learning outcomes using LKS teaching materials based on the study of ex-situ conservation area of Sumatran turtles in Taman Pintar pond. This research type is descriptive quantitative. Based on the results of data analysis, the environmental components in the ex-situ conservation area of Sumatran turtles in Taman Pintar pond gave the influences to the growth rate of the turtle which can be seen in the last year. the results of student learning outcomes after used LKS based on the study of ex-situ conservation area of Sumatran turtles in Taman Pintar pond also obtained an increasing result. The percentage of pretest is $48.4 \%$ and at the posttest increased to $90.9 \%$.
\end{abstract}

Keywords: Conservation area, Growth rate, Student Worksheet, Learning Outcomes.

\section{PENDAHULUAN}

Indonesia merupakan negara yang alamnya kaya terhadap keanekaragaman flora dan fauna. Namun, meskipun jenis flora dan fauna di Indonesia sangat bervariasi, jumlah populasi yang ada masih sangat kecil. Keterbatasan jumlah keanekaragaman yang terdapat di Indonesia ini membuat sebagian besar jenis flora dan fauna berada dalam kedudukan rawan. Kebutuhan manusia dan pemanfaatan kekayaan alam secara berlebihan tanpa dilakukannya penyeimbangan menjadi penyebab terancamnya kepunahan (Iskandar, 2000).
Penyebab utama kepunahan tumbuhan dan satwa diantaranya adalah kehilangan, kerusakan, serta terfragmentasinya habitat, pemanfaatan secara berlebihan, perburuan dan perdagangan ilegal. Hilang dan rusaknya habitat satwa disebabkan oleh berbagai aktivitas manusia, diantaranya konversi hutan alam untuk perkebunan, pembalakan liar (illegal logging) dan kebakaran hutan. Salah satu contoh dari keberagaman satwa yang ada di Indonesia yang sangat rentan mengalami kepunahan adalah kura-kura (Hanif dkk, 2008).

Kura-kura merupakan hewan yang kurang dianggap karena peranannya 
kurang berdampak bagi masyarakat Saat ini kura-kura menjadi komoditi ekspor yang menjanjikan peluang pemasaran bagi para eksportirnya. Kegiatan penangkapan kura-kura di alam tidak terlepas dari kegiatan perburuan yang dapat mengakibatkan kepunahan. Untuk mempertahankan jumlah keberadaan jenis kura-kura tersebut, perlu dilakukan upaya konservasi agar dapat mempertahankan sumber daya alam yang ada di dalamnya dan dapat dimanfaatkan demi masa depan yang akan datang (Iskandar, 2000).

Konservasi merupakan upaya pelestarian lingkungan dengan memperhatikan manfaat yang dapat diperoleh pada saat ini dan tetap mempertahankan keberadaan setiap komponen-komponen lingkungan untuk pemanfaatannya di masa yang akan datang. Upaya konservasi yang telah dilakukan diantaranya konservasi ex-situ yang dilakukan di kolam Taman Pintar (Suhartoyo dkk, 2016).

Kolam Taman Pintar merupakan salah satu lokasi konservasi ex-situ kura-kura yang terletak di depan Gedung Dekanat, Fakultas Keguruan dan IImu Pendidikan (FKIP) Universitas Bengkulu. Kolam Taman Pintar yang bukanlah habitat asli bagi hewan kura-kura Sumatera, diharapkan mampu menjadi tempat yang aman bagi kelestarian hidup kura-kura. Salah satu komponen pendukung keberhasilan konservasi kura-kura yaitu tersedianya pakan yang cukup serta habitat yang sesuai, karena suatu organisme dapat tumbuh dan berkembang hanya dalam batas-batas kisaran toleransi, kondisi faktor-faktor abiotik, dan ketersediaan sumber daya tertentu saja (Suhartoyo dkk, 2016). Untuk melihat pakan dan habitat yang sesuai terhadap kura-kura, perlu adanya bio indikator yang berpengaruh terhadap kawasan tersebut, yaitu dengan melihat pengaruh komponen biotik dan abiotik yang ada di kolam Taman Pintar
Hasil penelitian ini kemudian akan dikembangkan sebagai bahan ajar bagi siswa SMP. Dalam pembelajaran kurikulum 2013, seorang guru bukan hanya dituntut dalam penguasaan konsep yang sudah ada, namun seorang guru harus dapat melakukan sebuah eksplorasi menggunakan lingkungan sehingga dapat dijadikan sumber belajar berupa bahan ajar. Harapannya, siswa dapat lebih paham dan mengerti tentang konsep yang diajarkan guru, karena siswa belajar langsung dari lingkungannya (Putri, 2016).

Salah satu bahan ajar yang dirancang untuk memuat informasi mengenai kegiatan pembelajaran adalah lembar kerja siswa (LKS). Menurut Widjajanti (2008) mengemukakan bahwa LKS merupakan salah satu bahan ajar yang dapat dikembangkan oleh guru sebagai fasilitator dalam kegiatan pembelajaran. LKS yang baik adalah LKS yang dapat membantu siswa untuk lebih aktif dalam proses belajar mengajar, meningkatkan minat siswa dalam belajar, mampu menarik perhatian siswa, dan dapat meningkatkan kemampuan siswa dalam memecahkan masalah.

Berdasarkan informasi yang telah dilakukan dari hasil wawancara terhadap salah satu guru IPA di SMPN 1 Pondok Kelapa, bahan ajar yang digunakan guru masih berupa LKS yang berasal dari penerbit saja, yang berisi materi singkat, latihan soal dan disajikan secara tidak berwarna. Hal tersebut tentu saja mempengaruhi minat belajar siswa pada materi IPA karena tidak menyisipkan fakta atau fenomena yang terdapat di lingkungan secara nyata dan tidak dapat menuntun siswa memperoleh pengalaman belajar secara langsung, hal itu tentunya berdampak pada hasil belajar siswa yang belum mencapai nilai standar ketuntasan.

Agar siswa dapat memahami materi melalui fakta dan fenomena yang terdapat 
di lingkungan secara nyata dan dapat menuntun siswa memperoleh pengalaman belajar secara langsung, maka peneliti tertarik untuk mengembangkan sebuah bahan ajar berupa LKS berdasarkan studi kawasan konservasi ex-situ kura-kura Sumatera di kolam Taman Pintar dengan harapan dapat meningkatan hasil belajar siswa. Pengembangan LKS diterapkan dalam proses pembelajaran di kelas VII SMP, yakni pada materi pembelajaran interaksi makhluk hidup dengan lingkungannya. Kompetensi Dasar yang akan dicapai pada pembelajaran ini yaitu 3.8 menganalisis interaksi antara makhluk hidup dan lingkungannya.

Tujuan penelitian ini adalah mendeskripsikan pengaruh kawasan konservasi ex-situ kura-kura Sumatera di kolam Taman Pintar terhadap pertumbuhan kura-kura dan mendeskripsikan peningkatan hasil belajar siswa menggunakan bahan ajar LKS berdasarkan hasil studi kawasan konservasi ex-situ kura-kura Sumatera di kolam Taman Pintar.

\section{METODE}

Jenis penelitian ini adalah penelitian deskriptif kuantitatif. Dalam penelitian ini terdapat dua macam penelitian, yaitu penelitian sains dan penelitian pendidikan

Alat dan bahan yang digunakan dalam penelitian sains adalah meteran, tali rafia, pancang, bubuh, ember, termometer air, termometer suhu, termometer tanah, hygrometer, ph meter, timbangan digital camry, jangka sorong, jaring kura-kura, alat tulis dan kamera digital dengan bahan yaitu sampel hewan dan kura-kura yang tertangkap. Adapun alat dan bahan yang digunakan dalam penelitian pendidikan ini adalah alat tulis, lembar LKS, lembar tes, silabus SMP kelas VII, lembar Rencana Pelaksanaan Pembelajaran (RPP).

Subjek penelitian ini adalah seluruh siswa kelas $\mathrm{VII}_{\mathrm{A}}$ SMPN 1 Pondok Kelapa tahun ajaran 2016/2017 dengan jumlah siswa sebanyak 33 siswa yang terdiri dari 16 siswa laki-laki dan 17 siswa perempuan.

Data yang dikumpulkan yaitu data hasil observasi kawasan konservasi ex-situ di kolam Taman Pintar dan data hasil belajar siswa. Teknik yang digunakan untuk mengumpulkan data berupa observasi dan tes kognitif.

Instrumen penelitian terdiri atas lembar observasi kawasan konservasi exsitu di kolam Taman Pintar dan lembar tes tertulis. Lembar observasi kawasan konservasi ex-situ di kolam Taman Pintar digunakan untuk mengobservasi komponen biotik dan komponen abiotik yang terdapat di taman pintar. Komponen biotik diantaranya analisis vegetasi, morfometri kura-kura, dan data hewan yang ada di Taman Pintar. Lembar tes digunakan untuk mengetahui peningkatan hasil belajar siswa. Lembar tes hasil belajar terdiri atas 10 soal pilihan ganda. pretest dilakukan untuk mengetahui pengetahuan awal siswa sebelum diimplementasikan LKS. Postest digunakan untuk mengukur kemampuan siswa setelah menggunakan LKS.

Data hasil observasi kawasan konservasi ex-situ di kolam Taman Pintar dianalisis dengan menggunakan masingmasing rumus. Hasil analisa vegetasi tumbuhan akan dianalisis menggunakan rumus :

$$
I N P=K R+F R+D R
$$

Keterangan:

INP = Indeks Nilai Penting

$K R=$ Kerapatan relatif

$F R=$ Frekuensi relatif

$\mathrm{DR}=$ Dominansi Relatif

Hasil observasi hewan yang ada di dalam kolam Taman Pintar dianalisis menggunakan rata-rata ukuran morfometri tubuh berupa berat tubuh, panjang tubuh, tebal tubuh, dan lebar tubuh dari 
masing-masing hewan tersebut. Adapun rumusnya adalah

$$
\mathrm{X}=\frac{\sum X}{N}
$$

Keterangan:

$$
x=\text { Rata-rata }
$$

$\Sigma x=$ Jumlah ukuran morfometri pada hewan

$N=$ Jumlah seluruh ukuran morfometri pada hewan

Hasil observasi pertumbuhan kurakura dilakukan menggunakan rumus :

Pertumbuhan ukuran morfometri = pertumbuhan akhir - pertumbuhan awal pertumbuhan awal

Hasil data kemampuan kognitif siswa dianalisis dengan menghitung rerata, kategori rerata skor dan persentase ketuntasan seluruh siswa. Kategori rerata skor kemampuan kognitif mengacu pada kriteria ketuntasan minimum (KKM) SMPN 1 Pondok Kelapa yaitu $\geq 65$ berkategori tuntas dan $\leq 65$ berkategori tidak tuntas. Adapun persentase ketuntasan kemampuan kognitif siswa dianalisis dengan menggunakan rumus berikut Trianto (2011).

$$
\mathrm{KB}=\frac{N S}{N} \times 100 \%
$$

\section{Keterangan:}

$\mathrm{KB}=$ ketuntasan belajar klasikal

NS = jumlah siswa yang memperoleh nilai $\geq$ KKM

$\mathrm{N} \quad=$ jumlah seluruh siswa

\section{HASIL DAN PEMBAHASAN}

Dari hasil penelitian studi kawasan konservasi ex-situ kura-kura Sumatera yang telah dilakukan di kolam Taman Pintar Universitas Bengkulu dan implementasi Lembar Kerja Siswa (LKS) di SMPN 1 Pondok Kelapa diperoleh hasil sebagai berikut.

\section{Hasil dan Pembahasan deskripsi kawasan konservasi ex-situ kura-kura Sumatera di kolam Taman Pintar}

Analisa vegetasi tumbuhan dilakukan di kawasan konservasi ex-situ kura-kura Sumatera kolam Taman Pintar menggunakan metode transek kuadrat dengan petak berukuran $10 \mathrm{~m} \times 10 \mathrm{~m}$, yang diletakkan sepanjang jalur pengamatan. Jenis tumbuhan yang diamati adalah jenis tumbuhan tingkat pohon. Adapun hasil dari analisa vegetasi tumbuhan tersebut dapat dilihat pada Tabel 1. 
Tabel 1. Indeks Nilai Penting (INP) tumbuhan tingkat pohon pada plot ukuran $10 \mathrm{~m} \times 10 \mathrm{~m}$

\begin{tabular}{cccc}
\hline & Nama tumbuhan & Nama ilmiah & INP \\
\hline Plot 1 & Pohon sukun & Artocarpus altilis & $24,7 \%$ \\
& Kayu laban & Vitex pinnata & $134,2 \%$ \\
& Kayu balik angin & Mallotus paniculatus & $20,1 \%$ \\
\hline Plot 2 & Kayu gadis & Cinnamomum verum & $120,4 \%$ \\
& Kayu gadis & Cinnamomum verum & $120,4 \%$ \\
\hline Plot 3 & Kayu gadis & Cinnamomum verum & $120,4 \%$ \\
& Kayu gadis & Cinnamomum verum & $120,4 \%$ \\
& Kayu laban & Vitex pinnata & $134,2 \%$ \\
\hline Plot 4 & Kayu laban & Vitex pinnata & $134,2 \%$ \\
\hline Plot 5 & Kayu gadis & Cinnamomum verum & $120,4 \%$ \\
& Kayu laban & Vitex pinnata & $134,2 \%$ \\
\hline Plot 6 & Kayu laban & Vitex pinnata & $134,2 \%$ \\
& Kayu laban & Vitex pinnata & $134,2 \%$ \\
\hline
\end{tabular}

Rumus: INP $=(K R)+(D R)+(F R)$

Berdasarkan pada Tabel 1, dapat di simpulkan bahwa Indeks Nilai Penting (INP) pohon pada plot ukuran $10 \times 10 \mathrm{~m}$ di kawasan konservasi ex-situ kura-kura Sumatera di kolam Taman Pintar dimiliki oleh pohon laban (Vitex pinnata) yaitu $134,2 \%$, kemudian berturut-turut pohon kayu gadis (Cinnamomum verum) yaitu $120,4 \%$, selanjutnya pohon sukun (Artocarpus altilis) yaitu $24,7 \%$, dan INP terendah adalah kayu balik angin yaitu 20,1 $\%$.

Hasil observasi terhadap hewan yang merupakan komponen makhluk hidup yang ada pada kawasan konservasi ex-situ di kolam Taman Pintar dilakukan pada sebuah bubuh. Observasi terhadap hewan di lakukan dengan mengobservasi hewan jenis nekton. Nekton adalah hewan yang dapat bergerak bebas di air, seperti ikan, dan udang. Pengambilan data pada hewan ini bertujuan untuk mengetahui hewan yang dapat mewakili sebagai pakan kurakura.

Adapun hasil penangkapan hewan yang ada di dalam kolam Taman Pintar dapat di lihat pada tabel 2.

Tabel 2. Hasil penangkapan hewan yang ada di dalam kolam Taman Pintar

\begin{tabular}{cccccccc}
\hline Plot & $\begin{array}{c}\text { Stasiun } \\
\text { bubu ke- }\end{array}$ & Nama jenis & Jumlah & \multicolumn{4}{c}{ Rata-rata } \\
\cline { 4 - 8 } & & & & $\begin{array}{c}\text { Panjang } \\
(\mathbf{c m})\end{array}$ & $\begin{array}{c}\text { Lebar } \\
(\mathbf{c m})\end{array}$ & $\begin{array}{c}\text { Berat } \\
(\mathbf{g})\end{array}$ & $\begin{array}{c}\text { Tebal } \\
(\mathbf{m m})\end{array}$ \\
\hline \multirow{2}{*}{$\mathrm{A}$} & Satu & - & 0 & 0 & 0 & 0 & 0 \\
& Dua & Ikan sepat & 1 & 6,5 & 2,5 & 10,2 & 1,5 \\
& Tiga & - & 0 & 0 & 0 & 0 & 0 \\
\hline B & Satu & - & 0 & 0 & 0 & 0 & 0 \\
& Dua & Ikan mujair & 11 & 10,8 & 4,2 & 28 & 3,4 \\
& Tiga & - & 0 & 0 & 0 & 0 & 0 \\
\hline C & Satu & - & 0 & 0 & 0 & 0 & 0 \\
& Dua & Ikan sepat & 2 & 9 & 3,2 & 10,5 & 2,8 \\
& Tiga & - & 0 & 0 & 0 & 0 & 0 \\
\hline
\end{tabular}


Pengukuran berbagai komponen abiotik dilakukan setiap hari sekali selama satu minggu. Pengukuran faktor lingkungan ini bertujuan untuk mengetahui kondisi habitat yang sesuai terhadap pertumbuhan kura-kura. Adapun hasil pengukuran komponen abiotik yang dilakukan di kawasan konservasi ex-situ kura-kura Sumatera di kolam Taman Pintar dapat dilihat pada Tabel 3.

Tabel 3. Rentangan data hasil pengukuran komponen abiotik selama satu minggu

\begin{tabular}{ccc}
\hline No & Parameter & Rentang Nilai \\
\hline 1. & Suhu udara $\left({ }^{\circ} \mathrm{C}\right)$ & $26-29$ \\
2. & Suhu air $\left({ }^{\circ} \mathrm{C}\right)$ & $25-29$ \\
3. & Suhu tanah $\left({ }^{\circ} \mathrm{C}\right)$ & $27-29$ \\
4. & pH Air & $6-7$ \\
5. & Kelembaban udara & $62 \%-67 \%$ \\
\hline
\end{tabular}

Berdasarkan hasil pengukuran komponen abiotik yang telah dilakukan disimpulkan bahwa dalam satu minggu penelitian, diperoleh hasil yaitu suhu udara dalam kisaran $26-29\left({ }^{\circ} \mathrm{C}\right)$, Suhu air $25-29$ $\left({ }^{\circ} \mathrm{C}\right)$, Suhu tanah $27-29\left({ }^{\circ} \mathrm{C}\right), \mathrm{pH}$ Air $6-7$, Kelembaban udara $62 \%$ - $67 \%$.

Pengukuran laju pertumbuhan kurakura Garis Hitam (Cychlemis oldhamii) pertama diukur pada pelepasan kedua pada tanggal 11 Maret 2016 yang dilakukan oleh Marwinto Sinaga. Selanjutnya dilakukan pengukuran kembali pada tanggal 14 April 2017 oleh peneliti. Berdasarkan data awal dan data akhir hasil pengukuran laju pertumbuhan kura-kura Garis hitam (C. oldhamii) yang tertangkap di lokasi kawasan konservasi kolam Taman Pintar dengan kode tagging ABN dapat dilihat pada tabel 4.

Tabel 4. Data sampel kura-kura C. Oldhamii yang tertangkap selama dua pekan

\begin{tabular}{cccc}
\hline Laju pertumbuhan & $\begin{array}{c}\text { Awal (11 Maret 2016) } \\
\text { Oleh Marwinto Sinaga }\end{array}$ & $\begin{array}{c}\text { Akhir (14 April 2017) Oleh } \\
\text { Eria Irmawati }\end{array}$ & $\begin{array}{c}\text { Selisih } \\
\text { (\%) }\end{array}$ \\
\hline Kode Tagging & Tagging ABN & Tagging ABN & - \\
Jenis Kelamin & Betina & Betina & - \\
Berat tubuh & $741 \mathrm{~g}$ & $852 \mathrm{~g}$ & $111 \mathrm{~g}(14,9 \%)$ \\
Lebar karapaks & $19,0 \mathrm{~cm}$ & $19,5 \mathrm{~cm}$ & $0,5 \mathrm{~cm}(2,6 \%)$ \\
Lebar plastron & $11,8 \mathrm{~cm}$ & $12,1 \mathrm{~cm}$ & $0,3 \mathrm{~cm}(2,5 \%)$ \\
Panjang karapaks & $20,1 \mathrm{~cm}$ & $20,7 \mathrm{~cm}$ & $0,6 \mathrm{~cm}(2,9 \%)$ \\
Panjang plastron & $16,9 \mathrm{~cm}$ & $17,5 \mathrm{~cm}$ & $0,6 \mathrm{~cm}(3,5 \%)$ \\
Tebal tubuh & $6,4 \mathrm{~cm}$ & $6,6 \mathrm{~cm}$ & $0,2 \mathrm{~cm}(3,1 \%)$ \\
\hline
\end{tabular}

Berdasarkan Tabel 4, dapat dilihat bahwa hasil data pengukuran laju pertumbuhan kura-kura C.oldhamii yang di ukur pada 11 Maret 2016 sampai 14 April 2017 mengalami peningkatan, yaitu berupa peningkatan pertumbuhan berat tubuh 14,9\%, lebar karapaks 2,6\%, lebar plastron 2,5\%, panjang karapaks 2,9\%, panjang plastron 3,5\%, dan tebal tubuh 3,1 $\%$.

Berdasarkan hasil penelitian yang telah peneliti lakukan, kolam Taman Pintar memiliki komponen lingkungan yang mendukung terhadap pertumbuhan kurakura di kawasan tersebut. Komponen lingkungan tersebut berupa jenis pakan dan kondisi habitat yang ada di kolam Taman Pintar. Kolam Taman Pintar memiliki beragam jenis tumbuhan dan hewan yang dapat dijadikan sebagai sumber pakannya. Secara umum kondisi habitat kura-kura di lingkungan kolam Taman Pintar memiliki tipe habitat riparian. Kura-kura biasanya tinggal di dalam kolam, biasanya di bagian pinggir kolam yang memiliki lubang sebagai 
tempat persembunyiannya. Kondisi lingkungan kura-kura umumnya lembab karena terdapat di bawah pohon dan semak belukar (Apriyani dkk, 2015),

Sumber pakan kura-kura di kolam Taman Pintar dapat berasal dari tumbuhan dan hewan. Berdasarkan hasil studi di kolam Taman Pintar, tumbuhan-tumbuhan yang ada di sekitar kolam Taman Pintar beragam jenisnya dari tingkat pohon, semai, hingga tumbuhan bawah. Tumbuhan-tumbuhan ini diamati dengan tujuan untuk melihat apakah tumbuhantumbuhan tersebut memiliki fungsi dalam menaungi habitat kura-kura dan dapat menghasilan pakan bagi kura-kura. Jenisjenis tumbuhan penyusun habitat kurakura selengkapnya dapat dilihat pada Tabel 1.

Selanjutnya komponen lingkungan yang dapat dijadikan sebagai sumber pakan kura-kura adalah hewan yang ada di dalam kolam Taman Pintar. Berdasarkan hasil penelitian, hewan yang mewakili sebagai pakan kura-kura berupa nekton. Nekton merupakan organisme air yang dapat bergerak bebas, seperti udang, ikan sepat, dan ikan mujair. Masing-masing ukuran udang, ikan sepat, dan ikan mujair yang telah didapatkan saat penelitian dapat dilihat selengkapnya pada Tabel 2 . Hasil penelitian memperoleh nekton berupa udang, ikan sepat dan ikan mujair yang masih berukuran kecil kisaran 3,4 $10,8 \mathrm{~cm}$.

Selain sumber pakan yang menjadi faktor pendukung kebutuhan kura-kura, kondisi habitat yang ada di kolam Taman Pintar juga menjadi faktor terhadap kawasan konservasi ex-situ kura-kura. Kondisi habitat yang ada di kolam Taman Pintar dapat dilihat dari faktor abiotik lingkungan tersebut, diantaranya adalah suhu air, suhu udara, suhu tanah, $\mathrm{pH}$ air, dan kelembaban udara. Berdasarkan hasil penelitian faktor abiotik yang telah dilakukan di kolam Taman Pintar di peroleh hasil suhu air kisaran $25-29{ }^{\circ} \mathrm{C}$, suhu udara 26-29 ${ }^{\circ} \mathrm{C}$, suhu tanah $27-29{ }^{\circ} \mathrm{C}, \mathrm{pH}$ air 6-7, dan kelembaban udara $62 \%$ - 67\%. Hasil tersebut sesuai dengan pendapat yang menyatakan bahwa suhu yang cocok untuk pertumbuhan dan lingkungan hidup kurakura kisaran $24,4-27,8{ }^{\circ} \mathrm{C}$, untuk kelembaban udara sekitar $45 \%$ - 72\%, sedangkan untuk $\mathrm{pH}$ air berkisar antara 68 , dan pada suhu tersebutlah sistem daya tahan tubuh dapat bekerja dengan maksimal Puspitasari (2007).

Menurut Apriyani dkk (2015), habitat kura-kura C.oldhamii ini umunya adalah tipe habitat Semi Akuatik. Habitat semi akuatik adalah tipe habitat campuran yaitu daratan (tanah) dan air. Tipe habitat semi akuatik ini memiliki suhu yang cukup lembab karena berada di daratan (tanah) yang rerumputan, ditumbuhi tanaman semak dan belukar, dan dedaunan pohon yang jatuh ke tanah. Habitat yang lembab ini sangat cocok bagi kura-kura untuk hidup dan berkembang biak. Kura-kura tidak begitu suka dengan suhu yang panas, sehingga ketika di siang hari kura-kura akan mencari air untuk mendinginkan suhu badannya dan minum untuk menghilangkan rasa haus, setelah itu kembali lagi ke daratan untuk mencari tempat yang teduh, lembab, dan gelap untuk beristirahat. Kura-kura umunya menyukai tempat yang lembab gelap dan tempat yang kering gelap. Tempat yang gelap dapat membantu kura-kura untuk melindungi diri mereka dari pemangsa. Kura-kura menyukai tempat yang bersuhu lembab karena suhu yang lembab dapat menyesuaikan dengan kondisi tubuh mereka. Penyesuaian ini dilakukan karena kura-kura adalah jenis hewan yang berdarah dingin yang harus menyesuaikan suhu tubuh dengan lingkungan. Sedangkan untuk tempat kering gelap dimanfaatkan kura-kura untuk istirahat tidur di siang hari. Jenis kura-kura yang telah dikonservasi di kolam Taman Pintar adalah 
kura-kura Garis Hitam (Cyclemys oldhamii). Kura-kura C.oldhamii me-rupakan salah satu jenis kura-kura yang ada di Indonesia, kura-kura ini memiliki perisai punggung yang bergerigi umumnya kuning kecoklatan dengan tepi keping cenderung lebih gelap, perisai perut umunya berwarna kunig dengan ciri memiliki garisgaris hitam yang tebal dan tersusun pada setiap kepingnya (Iskandar, 2000).

Berdasarkan hasil penelitian terhadap kura-kura C.oldhamii di kawasan konservasi kolam Taman Pintar selama 2 minggu, kura-kura C.oldhamii yang tertangkap hanya 1 ekor dengan kode tagging $\mathrm{ABN}$. Pertumbuhan ukuran morfometri tubuh kura-kura C.oldhamii dengan kode tagging $A B N$ yang didapatkan mengalami peningkatan selama 1 tahun dari sejak pelepasan kedua bulan April 2016 - April 2017. Pertumbuhan berat badan C.oldhamii meningkat 14,9\%, pertumbuhan panjang karapaks 2,9\%, pertumbuhan lebar karapaks 2,6\%, pertumbuhan panjang plastron $3,5 \%$, pertumbuhan lebar plastron 2,5\%, sedangkan pertumbuhan tebal badan $3,1 \%$. Berdasarkan hasil yang didapat dari C.oldhamii tagging ABN dapat disimpulkan mengalami pe-ningkatan pertumbuhan ukuran mor-fometri tubuhnya.

Hasil belajar siswa menggunakan bahan ajar LKS berdasarkan hasil studi kawasan konservasi ex-situ kura-kura Sumatera di kolam Taman Pintar

Hasil studi kawasan konservasi di kolam Taman Pintar yang telah dilakukan dikembangkan ke dalam lembar kerja siswa sebagai bahan ajar. Lembar kerja siswa yang didesain memuat prosedur dan struktur yang tepat agar dapat digunakan sebagai bahan ajar yang baik. Menurut Prastowo (2011) yaitu agar siswa bisa memahami dan mengerti konsep serta pengetahuan yang terdapat dalam LKS, LKS yang dibuat harus berisi materi dan pertanyaan yang menggali kemampuan kognitif siswa. Selain itu, lembar kerja siswa ini didesain mengandung konsep nyata dari lingkungan alam sekitar siswa karena komponen lingkungan yang di amati hasil eksplorasi secara langsung. Hasil penelitian komponen lingkungan di kawasan konservasi di kolam Taman Pintar ini digunakan sebagai informasi yang memperkaya pengetahuan dalam lembar kerja siswa sehingga proses pembelajaran lebih menarik dan disertai informasi penelitian yang aktual.

Uji lapangan atau implementasi dilakukan pada kelas VII SMPN 1 Pondok Kelapa Kota Bengkulu dengan jumlah siswa sebanyak 33 orang. Pada penelitian ini, hasil belajar yang diukur adalah hasil belajar pada ranah kognitif saja. Berikut pengukuran hasil pretest dan postest siswa kelas VII A SMPN 1 Pondok Kelapa.

Tabel 5. Hasil penilaian pretest dan postest siswa kelas VII A SMPN 1 Pondok Kelapa Kota Bengkulu

\begin{tabular}{ccc}
\hline Interval (c) & \multicolumn{2}{c}{ Frekuensi } \\
\cline { 2 - 3 } & Pretest & Postest \\
\hline $40-50$ & 8 & 2 \\
$51-60$ & 9 & 1 \\
$61-70$ & 9 & 7 \\
$71-80$ & 6 & 5 \\
$81-90$ & 1 & 11 \\
$91-100$ & - & 7 \\
\hline Jumlah & 33 & 33 \\
\hline
\end{tabular}

Berdasarkan pada Tabel 5, hasil belajar yang diperoleh siswa saat pretest dan postest dapat disimpulkan bahwa pelaksanaan proses belajar menggunakan bahan ajar LKS dapat meningkatkan hasil belajar siswa. Prastowo (2011) menyatakan bahwa kegunaan LKS sebagai bahan ajar oleh guru yaitu untuk memancing siswa agar terlibat aktif dengan materi yang dibahas. 


\section{PENUTUP}

\section{Simpulan}

Berdasarkan penelitian yang telah dilakukan, maka dapat di ambil kesimpulan sebagai berikut:

a. Kawasan konservasi ex-situ kura-kura Sumatera di kolam Taman Pintar mempunyai pengaruh untuk mendukung laju pertumbuhan kurakura C. Oldhamii.

b. Melalui penggunaan bahan ajar LKS berdasarkan hasil studi kawasan konservasi ex-situ kura-kura Sumatera di kolam Taman Pintar dapat meningkatkan hasil belajar siswa pada penilaian kognitif. Peningkatan hasil belajar dapat dilihat hasil rata-rata nilai pretest dan postest.

\section{Saran}

Berdasarkan penelitian yang telah dilakukan, beberapa saran yang dapat dianjurkan yaitu :

a. Dalam penelitian di kolam Taman Pintar, perlu adanya penambahan waktu dalam penangkapan hewan di dalam kolam Taman Pintar dikarenakan waktu penangkapan 3 kali belum cukup untuk melakukan penelitian.

b. Untuk penelitian lebih lanjut, perlu adanya pembelajaran yang lebih akurat mengenai teknik pemasangan jaring kura-kura yang benar dan pemahaman yang lebih dalam mengenai umpan/makanan yang disukai kura-kura.

c. Dalam pembelajaran di sekolah, perlu adanya penambahan waktu dalam implementasi LKS.

\section{DAFTAR PUSTAKA}

Apriyani, Dwi, dkk. 2015. Jurnal Hutan Tropis. http://download.portalgaruda.org/a rticle. php ?article $=96165 \&$ val $=5070$ di akses pada tanggal 15 Mei 2017

Hanif, dkk. 2008. Konservasi Indonesia Sebuah Potret Pengelolaan dan Kebijakan.

http://pdf.usaid.gov/pdf_docs/Pnad u286.pdf di akses pada tanggal 5 Mei 2017

Iskandar, D.T. 2000. Kura-Kura dan Buaya Indonesia \& Papua Nugini. Bandung: PALMedia Citra

Prastowo, Andi. 2011. Panduan Kreatif Membuat Bahan Ajar Inovatif. Jogjakarta: Diva Press

Putri, NL. Kurnia. 2016. Kompetensi Profesional Guru Dalam Menyiapkan Konsep Materi Ajar Pkn Pada Smp Negeri $\quad 30 \quad$ Makassar. http://ojs.unm.ac.id/index.php/tom alebbi/article/viewFile/1654/696. Di akses pada tanggga 17 April 2017

Puspitasari, S. DKK. 2007. Prilaku Harian Labi-Labi (Amyda cartilaginea Boddaert) di Desa Belawa, Kabupaten Cirebon. https://www.researchgate.net/.../P ERILAKU-HARIAN-LABI-LABI-Amydacartilagine. Di akses pada tanggal21 Mei 2017

Sugiyono. 2008. Metode Penelitian Kunatitatif Kualitatif dan $R \& D$. Bandung: Alfabeta

Suhartoyo H, Anggraini, N,. Silviana, D.P,. dan Cempaka. I. 2016. Pendidikan Konservasi Kura-Kura Sumatera. Bengkulu: Fkip Unib

Trianto. 2011. Model Pembelajaran Terpadu. Jakarta: Bumi Aksara

Widjajanti, Endang. 2008. Kualitas Lembar Kerja Siswa. Makalah Pelatihan Penyusunan LKS. Yogyakarta: Jurusan Pendidikan Kimia FMIPA UNY. 